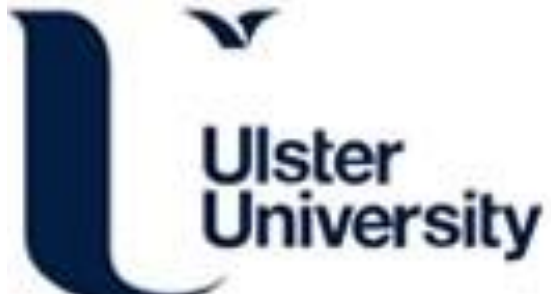

Three-dimensional analysis of intracycle velocity fluctuations in frontcrawl swimming

Psycharakis, S., Naemi, R., Connaboy, C., McCabe, C., \& Sanders, R. (2010). Three-dimensional analysis of intracycle velocity fluctuations in frontcrawl swimming. Scandinavian Journal of Medicine \& Science in Sports, 20(1), 128-135. https://doi.org/10.1111/j.1600-0838.2009.00891.x

Link to publication record in Ulster University Research Portal

Published in:

Scandinavian Journal of Medicine \& Science in Sports

Publication Status:

Published (in print/issue): 01/02/2010

DOI:

10.1111/j.1600-0838.2009.00891.x

Document Version

Publisher's PDF, also known as Version of record

\section{General rights}

Copyright for the publications made accessible via Ulster University's Research Portal is retained by the author(s) and / or other copyright owners and it is a condition of accessing these publications that users recognise and abide by the legal requirements associated with these rights.

\section{Take down policy}

The Research Portal is Ulster University's institutional repository that provides access to Ulster's research outputs. Every effort has been made to ensure that content in the Research Portal does not infringe any person's rights, or applicable UK laws. If you discover content in the Research Portal that you believe breaches copyright or violates any law, please contact pure-support@ulster.ac.uk. 


\title{
Three-dimensional analysis of intracycle velocity fluctuations in frontcrawl swimming
}

\author{
S. G. Psycharakis ${ }^{1,2}$, R. Naemi ${ }^{2}$, C. Connaboy ${ }^{1,2}$, C. McCabe $^{2}$, R. H. Sanders ${ }^{2}$ \\ ${ }^{1}$ School of Life Sciences, Napier University, Edinburgh, UK, ${ }^{2}$ Centre for Aquatics Research \& Education, University of Edinburgh, \\ Edinburgh, UK \\ Corresponding author: Stelios G. Psycharakis, School of Life Sciences, Napier University, 10 Colinton Road, Edinburgh, \\ EH10 5DT, Scotland, UK. Tel: +44 131 4552215, Fax: +44 131 4552291,E-mail: S.Psycharakis@napier.ac.uk
}

Accepted for publication 4 November 2008

The purpose of this study was to determine accurately the magnitude and changes of intra-cycle velocity fluctuation $\left(V_{\text {fluc }}\right)$, maximum $\left(V_{\text {max }}\right)$ and minimum velocity $\left(V_{\text {min }}\right)$ of the center of mass during a maximum $200 \mathrm{~m}$ frontcrawl swim, and to examine whether they are associated with performance. Performance was indicated by the mean velocity $\left(V_{\text {mean }}\right)$ of the stroke cycle (SC) in the swimming direction. The relative $V_{\text {fluc }}, V_{\max }$ and $V_{\min }$ were also calculated as a percentage of $V_{\text {mean, }}$ while $V_{\text {fluc }}$ was calculated for all three directions. Eleven male swimmers of national/international level participated in this study and their performance was recorded with four below- and two above-water-synchronized cameras. Four SCs were analyzed for the $200 \mathrm{~m}$ swim (one for each $50 \mathrm{~m}$ ). Anthropometric data were calculated by the elliptical zone method. $V_{\text {mean }}$ generally decreased throughout the test. $V_{\max }$ and $V_{\min }$ were positively correlated to performance and were significantly higher in SC1 than in the other SCs. However, the relative $V_{\max }$ and $V_{\min }$ values were remarkably consistent during the $200 \mathrm{~m}$ and not associated with performance. Despite the noteworthy magnitude of $V_{\text {fluc }}$ in all directions, they were in general not correlated with performance and there were no significant changes during the test.
In swimming, increasing recognition of the limitations of quantifying only race parameters such as stroke rate and stroke length has led to the evolution of biomechanical equipment and analysis methods, and more frequent quantification of other kinematic parameters related to swimming performance. The amplitude of velocity fluctuation $\left(V_{\text {fluc }}\right)$ of the center of mass $(\mathrm{CM})$ and the maximum $\left(V_{\max }\right)$ and minimum $\left(V_{\min }\right)$ instantaneous velocity reached during a stroke cycle (SC) have been some of the main kinematic parameters linked to swimming performance. For example, Togashi and Nomura (1992) stated that faster swimmers should be expected to have lower $V_{\text {fluc }}$ than slower swimmers, while Cappaert et al. (1995) suggested that elite swimmers minimize the reduction in swimming velocity $(V)$ caused during periods of the SC in which the propulsive forces are less than the resistive forces.

In view of the possible influence of $V_{\max }, V_{\min }$ and $V_{\text {fluc }}$ on performance, some investigators have calculated the magnitude of these parameters in swimming, predominantly for the breaststroke and butterfly strokes. However, there is some discrepancy in the findings of the studies in this area. For example, in some butterfly and breaststroke studies faster swimmers were found to have lower $V_{\text {fluc }}$ (Togashi \& Nomura, 1992; Sanders, 1996a, b) and higher $V_{\min }$ (Sanders, 1996a, b; D’Acquisto \& Costill,
1998; Takagi et al., 2004) than slower swimmers, while in other studies faster swimmers were found to have significantly higher $V_{\text {fluc }}$ (Leblanc et al., 2007) and $V_{\min }$ similar to slower swimmers (Manley \& Atha, 1992; Leblanc et al., 2007).

The discrepancies in the studies in this area might be partly explained by the differences between and the limitations of the methods used. For example, in most studies swimming $V$ was calculated as the $V$ of a fixed point on a swimmer's body (usually the hip), with the use of either two-dimensional (2D) videography (Togashi \& Nomura, 1992; D'Acquisto \& Costill, 1998; Takagi et al., 2004) or purpose-made devices, which were attached on the swimmers' necks or waists through a wire (Craig \& Pendergast, 1979; Alberty et al., 2005; Leblanc et al., 2007). However, recent studies have indicated that fixed points such as the hip do not represent accurately the intracycle behavior of the kinematic variables of the CM (Barbosa et al., 2003; Psycharakis \& Sanders, 2008). Moreover, Craig and Pendergast (1979) stated that purpose-made wire devices might not represent the movements of the $\mathrm{CM}$, and Leblanc et al. (2007) added that when such devices are used vertical movements of the hip can be misinterpreted as forward displacements and the swimmers' technique might be modified. Although some researchers have calculated the $V$ of the $\mathrm{CM}$ using 2D methods 
and assuming bilateral symmetry (Sanders, 1996a, b), recent studies have shown that technique asymmetries are frequently observed in $V$ patterns of swimmers (Keskinen \& Keskinen, 1997; Arellano et al., 2003), emphasizing further the need to assess accurately the intracycle $V$ of the $\mathrm{CM}$ with three-dimensional (3D) methods.

In addition to the above limitations, there are some areas that remain to be investigated. First, $V_{\text {fluc }}$ has been reported for one swimming length only and, further, $V_{\text {fluc }}$ in the lateral and vertical directions have not been considered as being very important, given the lack of attention to these variables in swimming texts and that $V_{\text {fluc }}$ has been calculated only for the direction of swimming. However, it would be of interest to also assess $V_{\text {fluc }}$ during the course of an event and for the vertical and lateral directions, for the purposes of investigating whether these variables are associated with performance and/or are influenced by performance deterioration during a swimming race. Second, in most studies just the absolute values have been calculated for $V_{\text {fluc }}, V_{\max }$ and $V_{\min }$. The calculation of the values of these variables relative to the mean $V$ during a given $\mathrm{SC}$ could be more informative with respect to their influence on swimming performance. Finally, it should be mentioned that although it is often expected that the relationship between performance and $V_{\text {fluc }}$ would be linear (e.g. Togashi \& Nomura, 1992) this might not have a fully justifiable scientific rationale. This is because $V_{\text {fluc }}$ is influenced by propulsive and resistive forces, which have a non-linear relationship with $V$ (e.g. Toussaint et al., 1988), and also given that the examination of the relationship between $V_{\text {fluc }}$ and performance does not take into account factors such as differences in the duration of the SC and the timing and duration of applied forces.

The purpose of this study was to determine accurately, in $3 \mathrm{D}$, the intracycle $V_{\text {fluc }}, V_{\max }$ and $V_{\min }$ of the CM in male frontcrawl swimmers across a $200 \mathrm{~m}$ maximum swim. The second purpose was to investigate whether $V_{\max }$ and $V_{\min }$ in the direction of swimming (referred to as "horizontal" from this point on) and the magnitude of $V_{\text {fluc }}$ in all directions have a linear relationship with performance. Performance was indicated by mean horizontal $V\left(V_{\text {mean }}\right)$. To obtain a more complete and clear indication of the influence of $V_{\text {fluc }}, V_{\max }$ and $V_{\min }$ on swimming performance, these variables were considered for both the absolute and the relative (calculated as percentage of the $V_{\text {mean }}$ ) values.

\section{Materials and methods}

\section{Subjects}

Eleven male frontcrawl swimmers participated in this study. The group consisted of senior swimmers of national level and junior swimmers of national and international levels. The descriptive characteristics of the group, expressed as mean \pm standard deviation (SD), were as follows: age: $16.9 \pm 1.2$ years; height: $180.8 \pm 5.7 \mathrm{~cm}$; and body mass: $71.4 \pm 5.6 \mathrm{~kg}$. The test procedures were approved by the institutional ethics committee and written informed consent forms were obtained from all subjects before the test.

\section{Experimental protocol}

All swimmers were tested around the mid-part of the season. Their training consisted of both aerobic and anaerobic intensity, with the training frequency and volume ranging from six to eight sessions per week and from 5 to $7 \mathrm{~km}$ per session, respectively. To minimize any overtraining effects on test performance, swimmers avoided stressful training during the days before the test day. On the testing day each swimmer performed a personalized warmup, which consisted of low- to moderate-intensity aerobic swimming, with elements of kick and drills, as well as short race pace sets totaling up to $1000 \mathrm{~m}$. Following the warmup, swimmers performed a $200 \mathrm{~m}$ maximum frontcrawl swim replicating their competition pacing and strategy. $200 \mathrm{~m}$ events are often used in swimming studies as their metabolic characteristics are considered important determinants of the behavior of the kinematic variables during these events (e.g. Barbosa et al., 2005; Psycharakis et al., 2008). Moreover, the $200 \mathrm{~m}$ frontcrawl event was one of the specialist events of all the swimmers who participated in this study.

All tests were conducted in a $25 \mathrm{~m}$ indoor pool and a push start was used to eliminate any influence of the dive on the kinematics of the SC analyzed for the first length. To eliminate the possible effects of breathing on the variables studied (Payton et al., 1999), swimmers were instructed to avoid breathing while swimming through the $6.5 \mathrm{~m}$ calibrated space. The personal best performance of the swimmers for the $200 \mathrm{~m}$ frontcrawl event was $122.5 \pm 4.5 \mathrm{~s}$. To ensure that test performance would be at a level similar to competition performance, considering the effect of the push start on the final time, a test requirement for each swimmer's $200 \mathrm{~m}$ time was $<105 \%$ of his personal best performance. All swimmers satisfied these criteria when first tested, as their actual performance on the test was $125.4 \pm 4.7 \mathrm{~s}$ or $3.0 \pm 1.5 \%$ slower than their personal best performance.

\section{Camera and calibration setup}

Each swimmer's performance was recorded with a total of six stationary and synchronized JVC KY32 CCD cameras at 50 fields/s with a shutter speed of $1 / 120 \mathrm{~s}$. Four cameras were below and two were above the water. A $6.75 \mathrm{~m}^{3}$ frame with orthogonal axes $(4.5 \times 1.5 \times 1 \mathrm{~m}$, for the $X, Y$ and $Z$ axes, respectively) was positioned so that half the frame was above and half below the water, with the $X$-axis aligned horizontally in the direction of swimming and the $Y$ and $Z$ axes being vertical and lateral, respectively. Each camera recorded a space $6.5 \mathrm{~m}$ long, extending $1 \mathrm{~m}$ beyond each side of the calibration frame for the $\mathrm{X}$-axis. The camera and frame positions are illustrated in Fig. 1.

The calibration setup has been described in detail and the accuracy and reliability of the calibration procedures have been established by Psycharakis et al. (2005). These procedures revealed small errors, indicating that the accuracy and reliability of coordinate reconstruction were in general similar to or better than other studies that used similar calibration volumes (e.g. Coleman \& Rankin, 2005). Moreover, considering that extrapolations beyond small calibration volumes 


\section{Psycharakis et al.}

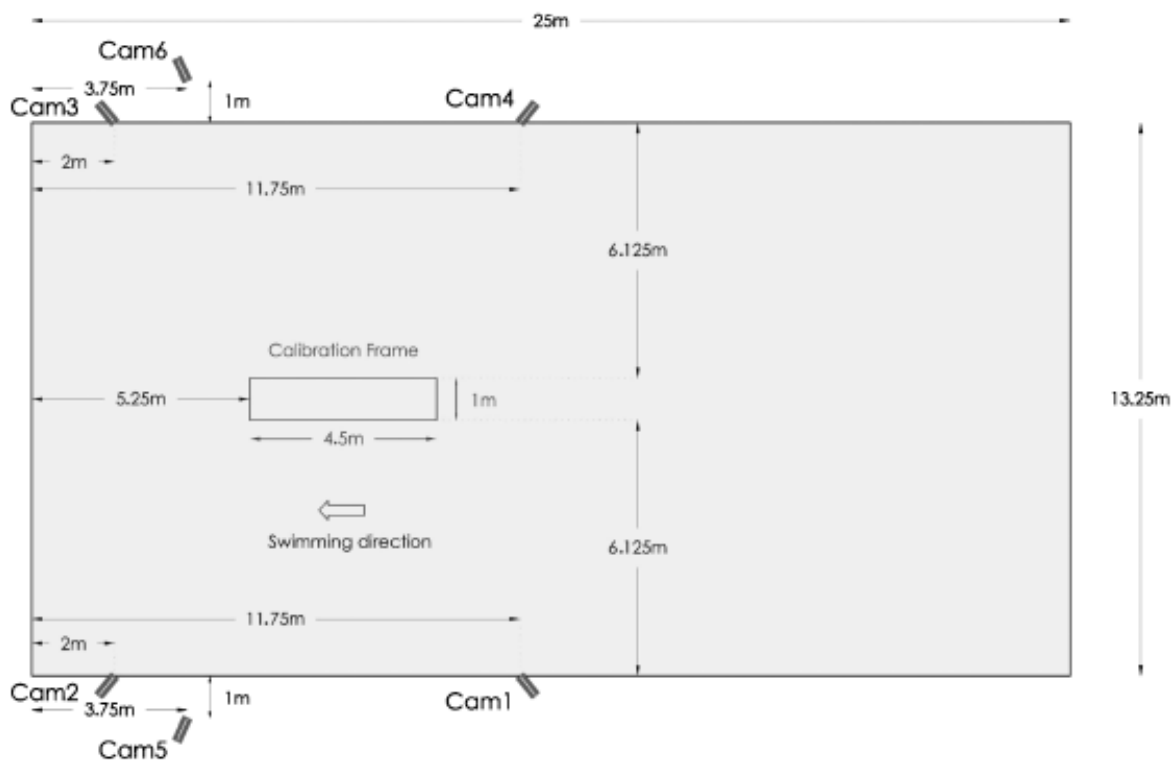

Fig. 1. Camera and calibration frame positions for the setup used for three-dimensional analysis. Note: Below water: cameras 1-4; above water: cameras 5 and 6 . increase reconstruction errors (Challis, 1995), the large calibration volume in the present study minimized the possibility of extrapolation beyond the space of interest, increasing further the accuracy of the measurements.

\section{Anthropometric data calculations}

Accurate analysis of intracyclic $V$ requires accurate measurement of the whole-body CM. This requires using a full-body model with accurate anthropometric data. The anthropometric data were obtained with the use of the elliptical zone method (Jensen, 1978), using PC software developed by Deffeyes and Sanders (2005). The accuracy of the elliptical zone method was assessed by calculating the difference between the estimated (obtained with digitizing) and the real (measured with a set of pre-calibrated laboratory scales) body mass values. The reliability of the elliptical zone method was obtained by repeated digitizing (10 times) of the same swimmer and calculation of the SD and coefficient of variation $(\mathrm{CV})$ of the whole body mass values.

\section{Data processing}

Nineteen body landmarks (vertex; shoulder, elbow, wrist, hip, knee, ankle and metaphalangeal joints; the end of the middle fingers and the big toes) were digitized for each field ( 50 fields/s) with the use of the Ariel Performance Analysis System (APAS). The calculation of $3 \mathrm{D}$ coordinates relied on the Direct Linear Transformation (DLT) method (Abdel-Aziz \& Karara, 1971) incorporated into APAS. The accuracy of locating submerged markers was maximized by having four cameras. This meant that for the vast majority of the digitized frames, each marker was clearly visible by at least two different cameras, minimizing the incidence of "guessed points" being used in the DLT calculation.

The above- and below-water sequences were digitized and transformed separately. Given that the same calibration frame (and, hence, same coordinate system) was used for the aboveand below-water space of interest, the different sequences were then combined into a single file without requiring any further data adjustments. A Fourier transform and inverse transform were used to filter and smooth the raw displacement data by retaining harmonics up to $6 \mathrm{~Hz}$ in the inverse transform.

\section{Data analysis}

One SC was recorded for each swimmer for each $50 \mathrm{~m}$ length. Thus, all the variables were calculated four times (for SCs 1, 2, 3 and 4) during the $200 \mathrm{~m}$ frontcrawl test. Means for each swimmer across SCs and group means for each variable of interest were also calculated.

The duration of each SC (s) was obtained from the video recordings. The $\mathrm{CM}$ displacement $(\mathrm{cm})$ was determined by the standard procedure of summing moments of the segment centers of mass about the $X, Y$ and $Z$ reference axes. The $V$ of the CM $(\mathrm{m} / \mathrm{s})$ was then obtained by differentiating the $\mathrm{CM}$ displacement data using the first central difference formula. $V_{\text {mean }}(\mathrm{m} / \mathrm{s})$ for each SC of each swimmer was calculated by dividing the $X$ displacement of the $\mathrm{CM}$ during the SC by the period of the SC. The distinct $V_{\max }$ and $V_{\min }(\mathrm{m} / \mathrm{s})$ were obtained from the intracycle $V$ data. The relative $V_{\max }$ and $V_{\min }$ were calculated as a percentage of $V_{\text {mean }}\left(\% V_{\text {mean }}\right)$. $V_{\text {fluc }}(\mathrm{m} / \mathrm{s})$ of the CM in each direction was calculated by subtracting the $V_{\min }$ from the $V_{\max }$ for each SC, while the relative $V_{\text {fluc }}$ for each direction was calculated as a percentage of $V_{\text {mean }}\left(\% V_{\text {mean }}\right)$.

Digitizing reliability: One complete SC of one swimmer was digitized 10 times for all six cameras. For each variable of interest, the SD and CV across all digitizations were calculated as an indication of reliability.

\section{Statistical analysis}

To identify the significance of changes in variables across the stages of the swim, repeated measures analysis of variance (ANOVA) was performed among SCs 1, 2, 3 and 4. For all the repeated measures ANOVAs, the assumption of sphericity was tested. As this assumption was not violated, no further adjustments of the values were required. In addition to the original repeated measures ANOVA for the four SCs, post hoc tests were conducted to identify the significance of the findings for different pairs of SCs. To eliminate the possibility of type I errors in these post hoc tests, a Bonferroni adjustment to reduce the alpha level was applied as described by Vincent (2005).

Given that $V_{\text {mean }}$ was the performance measure, $V_{\max }, V_{\min }$ and $V_{\text {fluc }}$ were examined in relation to $V_{\text {mean }}$ throughout the $200 \mathrm{~m}$. To assess the nature and strength of correlations between these variables for each of the race stages, the Pearson's product-moment correlation coefficient $(r)$ was calculated. This meant that there were 11 scores (one for 
Analysis of intracycle velocity fluctuations

each participant) for each variable for each race stage (SCs 1-4 and mean $200 \mathrm{~m}$ scores). The exact $P$ values were calculated and statistical significance was accepted at $P<0.05$. All statistical analyses were conducted with the use of the Statistical Package for Social Sciences (SPSS) 14.0 software.

\section{Results}

Accuracy and reliability of calculations

The calculations showed small and acceptable digitizing errors for the kinematic variables. Table 1 shows the reliability calculations for each kinematic variable of interest. With respect to the accuracy of the elliptical zone method, the mean $( \pm \mathrm{SD})$ differences between estimated and real values were $-0.2 \pm 0.9 \mathrm{~kg}$ or $-0.3 \pm 1.3 \%$ (expressed as the percentage of the real body mass values). The RMS errors for the absolute and percentage differences were $0.9 \mathrm{~kg}$ and $1.3 \%$, respectively. The reliability calculations indicated low and acceptable SD $(0.4 \mathrm{~kg})$ and CV $(0.3 \%)$ values. The errors found in this study were in general smaller than those reported in most studies in which the elliptical zone method had been used (e.g. Jensen, 1978; Sanders et al., 1991).

\section{Maximum and minimum instantaneous velocity}

Figure 2 shows the changes in $V_{\text {mean }}, V_{\max }, V_{\min }$, relative $V_{\max }$ and relative $V_{\min }$ across the test, while Table 2 shows the repeated ANOVAs performed for these variables. Swimmers' $V_{\text {mean }}$ decreased with each $\mathrm{SC}$, with the exception of SC4, where $V_{\text {mean }}$ was not significantly different from $\mathrm{SC} 3 . V_{\max }$ and $V_{\min }$ were significantly higher in $\mathrm{SC}$ than in the other three $\mathrm{SCs}$, while $V_{\max }$ in $\mathrm{SC} 2$ was also significantly higher than in SC4. However, no significant changes were found for the relative $V_{\max }$ and $V_{\min }$. The values for relative $V_{\max }$ and $V_{\min }$ were remarkably similar throughout the test, with the mean $200 \mathrm{~m}$ values being $110.8 \pm 1.6 \%$ and $88.6 \pm 1.7 \%$, respectively. Swimmers spent less time $(P \leq 0.001)$ in SC1 $(1.27 \pm 0.15 \mathrm{~s})$ than in SC2 $(1.42 \pm 0.20 \mathrm{~s}), \mathrm{SC} 3(1.42 \pm 0.20 \mathrm{~s})$ and

Table 1. Reliability of kinematic variables

\begin{tabular}{lrl}
\hline Variables & SD & CV \\
\hline$V_{\text {mean }}(\mathrm{m} / \mathrm{s})$ & $<0.01$ & 0.09 \\
$V_{\max }(\mathrm{m} / \mathrm{s})$ & 0.03 & 1.18 \\
Relative $V_{\max }\left(\%\right.$ of $\left.V_{\text {mean }}\right)$ & 1.45 & 1.77 \\
$V_{\min }(\mathrm{m} / \mathrm{s})$ & 0.03 & 1.89 \\
Relative $V_{\min }\left(\%\right.$ of $\left.V_{\text {mean }}\right)$ & 1.98 & 2.41 \\
Horizontal $V_{\text {fluc }}(\mathrm{m} / \mathrm{s})$ & 0.03 & 3.67 \\
Relative horizontal $V_{\text {fluc }}\left(\%\right.$ of $\left.V_{\text {mean }}\right)$ & 1.59 & 3.27 \\
Vertical $V_{\text {fluc }}(\mathrm{m} / \mathrm{s})$ & 0.02 & 3.29 \\
Relative vertical $V_{\text {fluc }}\left(\%\right.$ of $\left.V_{\text {mean }}\right)$ & 1.15 & 2.88 \\
Lateral $V_{\text {fluc }}(\mathrm{m} / \mathrm{s})$ & 0.02 & 3.71 \\
Relative lateral $V_{\text {fluc }}\left(\%\right.$ of $\left.V_{\text {mean }}\right)$ & 1.25 & 3.96 \\
\end{tabular}

$V_{\text {mean }}$, mean velocity; $V_{\max }$, maximum velocity; $V_{\text {fluc }}$, velocity fluctuations; $\mathrm{SD}$, standard deviation; CV, coefficient of variation.

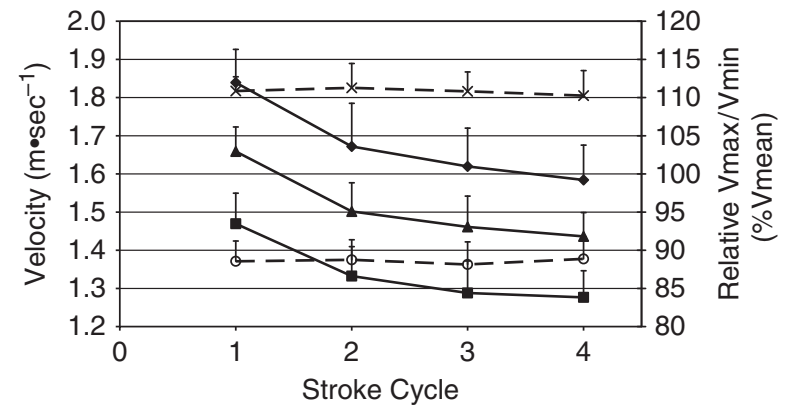

$\rightarrow$ Vmax $\rightarrow-$ Vmin $₫-$ Vmean $\leadsto$-Relative Vmax $\rightarrow$-Relative Vmin

Fig. 2. $V_{\text {mean }}, V_{\max }, V_{\min }$, relative $V_{\max }$ and relative $V_{\min }$ of the $\mathrm{CM}$ in the swimming direction during the $200 \mathrm{~m}$. $V_{\text {mean }}$, mean velocity; $V_{\max }$, maximum velocity; $V_{\min }$, minimum velocity; CM, center of mass.

Note: Values in the right $y$-axis represent the relative $V_{\max }$ and $V_{\min }$ values.

$\mathrm{SC} 4(1.40 \pm 0.17 \mathrm{~s})$. No other changes were found for any other pairs of SCs.

The correlations among $V_{\text {mean }}, V_{\max } / V_{\min }$ and relative $V_{\max } / V_{\min }$ are shown in Table $3 . V_{\text {mean }}$ had a very high, positive and significant correlation with both $V_{\max }$ and $V_{\min }$ throughout the test. Nevertheless, the correlations between $V_{\text {mean }}$ and relative $V_{\max } / V_{\min }$ were very low and not significant (with the exception of relative $V_{\max }$ for the mean $200 \mathrm{~m}$ values).

\section{Velocity fluctuations}

Figure 3 shows the changes in $V_{\text {fluc }}$ and relative $V_{\text {fluc }}$ in all directions across the test. Only minor changes were observed in the values of each variable during the test, with no significant changes for $V_{\text {fluc }}$ or relative $V_{\text {fluc }}$ during the test for any directions.

Table 4 shows the correlations between $V_{\text {mean }}, V_{\text {fluc }}$ and relative $V_{\text {fluc }}$ in all directions. With only a few exceptions throughout the test, the correlations were low and not significant.

\section{Discussion}

\section{Maximum and minimum instantaneous velocity}

As expected, $V_{\text {mean }}$ generally decreased throughout the test and SC time was significantly lower in SC1 than the other three SCs. $V_{\max }$ and $V_{\min }$ were significantly higher in SC1 than the other three SCs. It would be logical to expect swimmers to produce higher $V_{\max }$ and $V_{\min }$ at the early stages of the test. It is possible that, as the swim progressed, deterioration of the swimming technique due to factors such as fatigue could have had a negative effect on the ability of swimmers to produce large propulsive forces and/or to minimize resistive forces within an SC. 


\section{Psycharakis et al.}

Table 2. Significance levels of the repeated measures ANOVA for $V_{\text {mean }}, V_{\max }, V_{\min }$, relative $V_{\max }$ and relative $V_{\min }$

\begin{tabular}{llllll}
\hline & $V_{\text {mean }}$ & $V_{\max }$ & Relative $V_{\text {max }}$ & $V_{\text {min }}$ & Relative $V_{\text {min }}$ \\
\hline Overall & $F_{3,30}=92.3$ & $F_{3,30}=62.3$ & $F_{3,30}=0.3$ & $F_{3,30}=28.0$ & $F_{3,30}=0.2$ \\
& $(<0.001)$ & $(<0.001)$ & $(0.840)$ & $(<0.001)$ & $(0.811)$ \\
SC1/SC2 & $<0.001$ & $<0.001$ & 1.000 & 0.001 & 1.000 \\
SC1/SC3 & $<0.001$ & $<0.001$ & 1.000 & $<0.001$ & 1.000 \\
SC1/SC4 & $<0.001$ & $<0.001$ & 1.000 & 0.001 & 1.000 \\
SC2/SC3 & 0.008 & 0.350 & 1.000 & 0.135 & 1.000 \\
SC2/SC4 & 0.018 & 0.040 & 1.000 & 1.000 & 1.000 \\
SC3/SC4 & 1.000 & 0.455 & 1.000 & & 1.000 \\
\hline
\end{tabular}

Significant at $P<0.05$.

$V_{\text {mean }}$, mean velocity; $V_{\max }$, maximum velocity; $V_{\min }$, minimum velocity; SC, stroke cycle.

Table 3. Correlation coefficients and statistical significance ( $P$ values shown in the parentheses) for the correlations between $V_{\text {mean }}$ and $V_{\text {max }} / V_{\text {min }}$

\begin{tabular}{|c|c|c|c|c|c|}
\hline \multirow[t]{2}{*}{ Variable } & \multicolumn{5}{|c|}{ Correlations with $V_{\text {mean }}$} \\
\hline & $\mathrm{SC} 1$ & $\mathrm{SC} 2$ & $\mathrm{SC} 3$ & SC4 & Mean \\
\hline $\begin{array}{l}V_{\max } \\
V_{\min } \\
\text { Relative } V_{\max } \\
\text { Relative } V_{\min }\end{array}$ & $\begin{array}{l}0.94(<0.001) \\
0.84(0.001) \\
0.34(0.306) \\
0.22(0.516)\end{array}$ & $\begin{array}{c}0.92(<0.001) \\
0.86(<0.001) \\
0.43(0.187) \\
-0.01(0.977)\end{array}$ & $\begin{array}{c}0.93(<0.001) \\
0.87(<0.001) \\
0.13(0.703) \\
0.03(0.930)\end{array}$ & $\begin{array}{l}0.87(<0.001) \\
0.81(0.003) \\
0.21(0.535) \\
0.04(0.907)\end{array}$ & $\begin{array}{c}0.98(<0.001) \\
0.92(<0.001) \\
0.65(0.030) \\
-0.07(0.838)\end{array}$ \\
\hline
\end{tabular}

Significant at $P<0.05$.

$V_{\text {mean }}$, mean velocity; $V_{\max }$, maximum velocity; $V_{\min }$, minimum velocity; SC, stroke cycle.

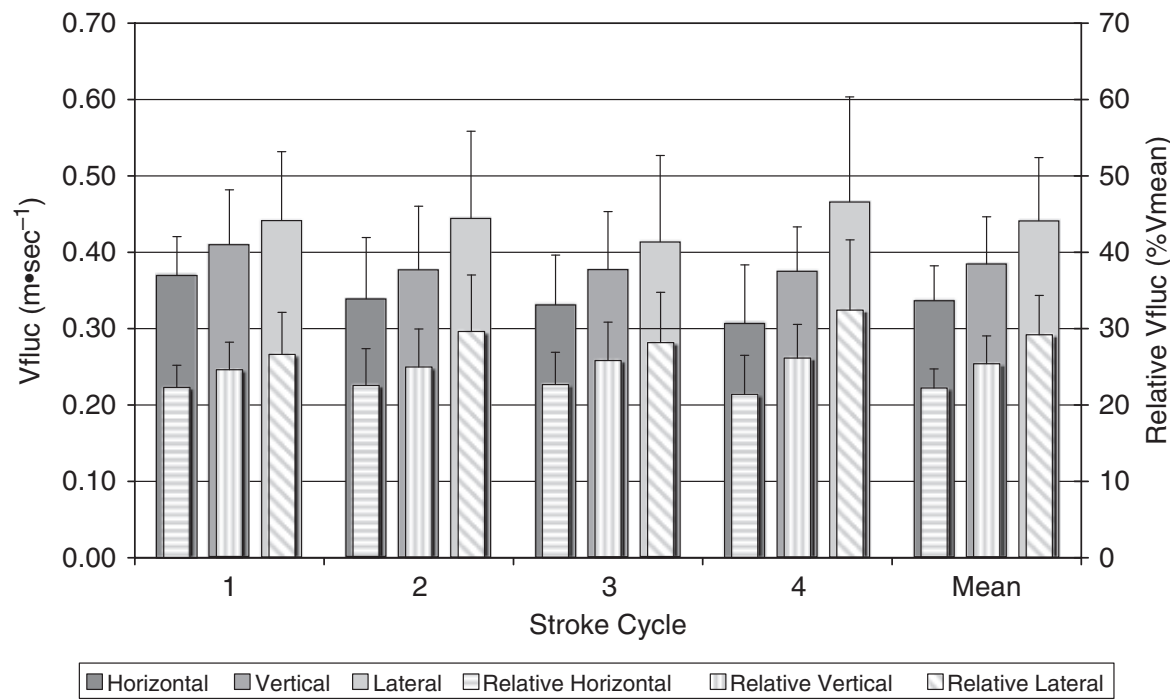

Fig. 3. Intracycle $V_{\text {fluc }}$ and relative $V_{\text {fluc }}$ of the center of mass in all directions during the $200 \mathrm{~m}$. $V_{\text {fluc }}$, velocity fluctuations. Note: Values in the right $y$-axis represent the relative $V_{\text {fluc }}$ values.

Table 4. Correlation coefficients and statistical significance ( $P$ values shown in the parentheses) for the correlations between $V_{\text {mean }}, V_{\text {fluc }}$ and relative $V_{\text {fluc }}$ in all directions

\begin{tabular}{|c|c|c|c|c|c|}
\hline \multirow[t]{2}{*}{ Variable } & \multicolumn{5}{|c|}{ Correlations with $V_{\text {mean }}$} \\
\hline & SC1 & $\mathrm{SC} 2$ & SC3 & SC4 & Mean \\
\hline Horizontal $V_{\text {fluc }}$ & $0.29(0.387)$ & $0.48(0.135)$ & $0.32(0.337)$ & $0.30(0.370)$ & $0.70(0.017)$ \\
\hline Relative horizontal $V_{\text {fluc }}$ & $0.02(0.954)$ & $0.29(0.387)$ & $0.05(0.884)$ & $0.11(0.748)$ & $0.46(0.155)$ \\
\hline Vertical $V_{\text {fluc }}$ & $0.85(<0.001)$ & $0.59(0.056)$ & $0.36(0.277)$ & $-0.07(0.838)$ & $0.61(0.046)$ \\
\hline Relative vertical $V_{\text {fluc }}$ & $0.78(0.005)$ & $0.44(0.176)$ & $0.09(0.792)$ & $-0.33(0.322)$ & $0.39(0.236)$ \\
\hline Lateral $V_{\text {fluc }}$ & $0.01(0.977)$ & $0.22(0.516)$ & $0.62(0.042)$ & $0.23(0.496)$ & $0.32(0.337)$ \\
\hline Relative lateral $V_{\text {fluc }}$ & $-0.18(0.596)$ & $0.02(0.954)$ & $0.47(0.145)$ & 0.07 (0.838) & $0.09(0.792)$ \\
\hline
\end{tabular}

Significant at $P<0.05$.

$V_{\text {fluc }}$, velocity fluctuations; SC, stroke cycle. 
Swimming performance (as indicated by $V_{\text {mean }}$ ) had a strong linear relationship with both $V_{\max }$ and $V_{\min }$ throughout the $200 \mathrm{~m}$. In contrast to the absolute $V_{\max }$ and $V_{\min }$ values, the relative values for these variables showed a noteworthy consistency throughout the test and were not associated with swimming performance. Regardless of the swimmers' level, the relative $V_{\max }$ and $V_{\min }$ were approximately $11 \%$ higher and lower, respectively, than $V_{\text {mean }}$. These resulted in the relative $V_{\text {fluc }}$ for the swimming direction being consistent at approximately $22 \%$ of $V_{\text {mean }}$. This is an important finding, which suggests that when $V_{\text {mean }}$ is taken into consideration for calculations of the relative values, $V_{\max }, V_{\min }$ and $V_{\text {fluc }}$ in the swimming direction are consistent and not linked to swimming performance. Nevertheless, it might be possible that the group of swimmers tested in this study was too homogenous and might have hindered any relationships between these variables and performance. Further research on swimmers of different levels (e.g. novice swimmers) would be useful for the purposes of confirming and generalizing these findings.

The values found for $V_{\max }$ and $V_{\min }$ in the present study were much closer to $V_{\text {mean }}$ than the values reported in other frontcrawl studies. Alberty et al. (2005) found the relative $V_{\max }$ and $V_{\min }$ to be approximately $124 \%$ and $79 \%$, respectively, of $V_{\text {mean }}$, while Craig and Pendergast (1979) reported values for $V_{\max }$ and $V_{\min }$ that were approximately $20 \%$ higher and lower, respectively, than $V_{\text {mean }}$. However, it should be noted that in both studies $V$ was measured with the use of purpose-made devices that did not measure the $V$ of the CM and, thus, the possible limitations associated with this design (as outlined in the introduction) might have affected the accuracy of $V$ calculations.

\section{Velocity fluctuations}

Fluctuations of $V$ in the swimming direction are expected due to the variation in the magnitude and direction of longitudinal resultant forces produced during an SC. As it is also suggested by recent research evidence (Toussaint et al., 2002), vertical and lateral $V_{\text {fluc }}$ would be caused by forces having components other than along the horizontal line in the direction of intended travel. Vertical $V_{\text {fluc }}$ may also be due to changes in the magnitude of buoyancy relative to gravitational forces. However, even though one would expect some $V_{\text {fluc }}$ in these directions, it is noteworthy that the lateral and vertical $V_{\text {fluc }}$ were larger than those in the swimming direction for both the absolute and the relative values. Despite these fluctuations not being significantly correlated with performance in most SCs, future research needs to be conducted to investigate more closely their causes and effects, especially for strokes with pronounced vertical movements such as butterfly and breaststroke. Identification of the influence of such fluctuations on swimming kinematics could provide important information to swimmers and coaches that would facilitate the improvement of swimming performance.

Considering that resistive forces are expected to be proportional to the square of $V$, a decrease in $V_{\max }$ during the test would mean that swimmers would have to overcome lower resistive forces. Although one could expect such changes in resistive forces to cause changes in the magnitude of $V_{\text {fluc }}, V_{\text {fluc }}$ did not change as performance deteriorated during the $200 \mathrm{~m}$ test. Thus, although the swimmers' ability to overcome resistive forces might reduce with fatigue during the course of the race, a possible decrease in the magnitude of resistive forces during the $200 \mathrm{~m}$ might explain the fact that the decrease in $V$ (and, therefore, the $V_{\text {fluc }}$ ) remained similar to that of the early stages of the race. Further, given the changes in SC time during the test, factors such as the timing, duration and direction of propulsive and resistive forces could have changed. In view of this possibility, future research could improve the understanding of the causes of $V_{\text {fluc }}$ during an SC by exploring the intracycle changes in the balance between propulsive and resistive forces with a detailed analysis of variables such as the patterns, number and timing of intracycle $V$ and acceleration maxima and minima.

In general, $V_{\text {fluc }}$ in all directions was not associated with performance. However, it should be noted that in the few SCs for which significant correlations were identified between $V_{\text {fluc }}$ and performance in the present study, faster swimmers had larger fluctuations than slower swimmers. The latter implied that a higher $V_{\text {mean }}$ might be associated with a larger $V_{\text {fluc }}$ due to the larger resistive forces applied on the swimmers. In other frontcrawl studies, Alberty et al. (2005) also found no link between $V_{\text {fluc }}$ and performance, while Craig and Pendergast (1979) reported that $V_{\text {fluc }}$ tended to increase with $V$ but no differences were found when the relative $V_{\text {fluc }}$ were taken into account. It should be noted though that many researchers have used different approaches for calculation of $V_{\text {fluc }}$. For example, methods that have been used for calculation of $V_{\text {fluc }}$ include, among others, calculation of the $\mathrm{CV}$ of the $V$ signal of the relative maximum and minimum values (e.g. Alberty et al., 2005) and calculation of an index of fluctuation (in breaststroke) that combined the peak velocities of the arm and the leg phase and the minimum velocities of the leg-arm lag phase and the recovery phase (e.g. Vilas-Boas, 1996; Leblanc et al., 2007). Therefore, when comparing different studies where the relationship between $V_{\text {fluc }}$ and performance was assessed, in addition to the methodological differ- 


\section{Psycharakis et al.}

ences/limitations outlined in the introduction, researchers should interpret and generalize their conclusions with consideration of the differences in the methods of calculation of $V_{\text {fluc }}$.

Although there was no association between $V_{\text {fluc }}$ and performance in the present study, it might be reasonable to assume that swimming with less $V_{\text {fluc }}$ for a given $V_{\text {mean }}$ would be more economical and require less energy expenditure. For example, VilasBoas (1996) reported that high $V_{\text {fluc }}$ were associated with a high energy cost when intra-individual data from breaststroke swimmers were considered. Barbosa et al. (2005) also reported that the energy cost increased with $V_{\text {fluc }}$ in butterfly swimmers. Thus, an important practical implication would be to identify for individual swimmers the differences in the kinematic characteristics between SCs of different $V_{\text {fluc }}$ for a given $V_{\text {mean }}$. This information would be useful for swimmers and coaches as it could provide guidance for the most effective technique for a given $V_{\text {mean }}$, therefore minimizing the energy demands.

It might also be possible that the relationship between $V_{\text {fluc }}$ and $V_{\text {mean }}$ does exist but is not linear. For example, preliminary data reported recently by Barbosa et al. (2006) implied that the polynomial approach might produce a better adjustment than the linear approach for the relationship between $V_{\text {fluc }}$ and $V_{\text {mean }}$. Further, $V_{\text {fluc }}$ is generally expected to be associated with the swimmers' effectiveness in the application of propulsive forces and their ability to minimize resistive forces. It has been suggested that propelling efficiency is directly related to the power applied by the swimmers to overcome drag and give the masses of water pushed away a kinetic energy change (Toussaint \& Beek, 1992). Given that power is a function of $V$ cubed (Barbosa et al., 2005) and resistive forces a function of $V$ squared (Toussaint et al., 1988), it would be of interest in future studies to explore ways of normalizing the $V$ changes to take into account the non-linear relationship between $V$ and propulsive/resistive forces. This would allow researchers to examine whether strong associations between intracycle $V$ changes and performance exist for the normalized $V$ values.

In view of the results of this study, our understanding of the causes of $V_{\text {fluc }}$ during an event could be further improved by separate analysis of the different phases of the SC (e.g. catch, pull, push and recovery). Such an analysis could also benefit from consideration of adaptations in swimmers' coordination, with the use of measures such as the index of coordination (Chollet et al., 2000), which explore the temporal characteristics of the phases of the SC. For example, it would be interesting to examine whether there are differences in $V_{\text {fluc }}$ for the different phases of an SC, and whether any changes in the $V_{\text {fluc }}$ of different SC phases are associated with changes in swimmers' coordination. Finally, it should be mentioned that only non-breathing SCs were analyzed in the present study. However, there is evidence that breathing affects swimming kinematics (e.g. Payton et al., 1999). Given that swimmers use both breathing and non-breathing SCs during a race, it would be of interest to explore the differences in $V_{\text {fluc }}$ between breathing and non-breathing SCs, as well as the influence of preferred vs non-preferred breathing side on the magnitude of $V_{\text {fluc }}$.

\section{Perspectives}

The existing body of knowledge was based mainly on $2 \mathrm{D}$ studies and single $\mathrm{SC}$ analyses and, despite the interesting findings, the reported data were inconclusive with respect to the relationships of $V_{\text {fluc }}, V_{\max }$ and $V_{\min }$ with performance. The 3D methods and accurate anthropometric data used in the present study allow some conclusions to be drawn. First, $V_{\max }$ and $V_{\min }$ were good indicators of performance and their changes during the test were similar to those of $V_{\text {mean }}$. However, the relative $V_{\min }$ and $V_{\max }$ values were remarkably consistent and not correlated with performance. Second, $V_{\text {fluc }}$ and relative $V_{\text {fluc }}$ in all directions did not have a linear relationship with performance and did not change significantly during the test. Interestingly, $V_{\text {fluc }}$ were higher in the lateral and vertical than in the swimming direction. The latter findings suggest that future research is required to investigate more closely their causes and effects, especially for strokes with pronounced vertical movements such as butterfly and breaststroke, as well as the possibility of a non-linear relationship between $V_{\text {fluc }}$ and performance. Finally, our understanding of the relationships between performance and $V_{\text {fluc }}$ could be further improved by a detailed analysis of the different phases of the SC as well as consideration of differences in $V_{\text {fluc }}$ between breathing and nonbreathing SCs.

Key words: biomechanics, kinematics, freestyle, center of mass.

\section{References}

Abdel-Aziz YI, Karara HM Direct linear transformation from comparator coordinates into object space coordinates in close range photogrammetry. In: American Society of Photogrammetry Symposium on Close Range Photogrammetry ed. Falls Church, VA: American
Society of Photogrammetry, 1971: $1-18$.

Alberty M, Sidney M, Huot-Marchand F, Hespel JM, Pelayo P. Intracyclic 


\section{Analysis of intracycle velocity fluctuations}

velocity variations and arm coordination during exhaustive exercise in front crawl stroke. Int $\mathbf{J}$ Sports Med 2005: 26(6): 471-475.

Arellano R, Lopez-Contreras G, Sanchez-Molina JA. Qualitative evaluation of technique in international Spanish junior and pre-junior swimmers: an analysis of error frequencies. In: Chatard JC, ed. Biomechanics and medicine in swimming IX. St Etienne: University of St Etienne Publications, 2003: 87-92.

Barbosa T, Keskinen KL, Fernandes ER, Colaco P, Lima AB, Vilas-Boas JP. Energy cost and intracyclic variation of the velocity of the centre of mass in butterfly stroke. Eur J Appl Physiol 2005: 93(5-6): 519-523.

Barbosa T, Santos Silva JV, Sousa F, Vilas-Boas JP Comparative study of the response of kinematical variables from the hip and the center of mass in butterfliers. In: Chatard JC, ed.

Biomechanics and medicine in swimming IX. St Etienne: University of St Etienne Publications, 2003: 93-98.

Barbosa TM, Lima F, Portela A, Novais D, Machado L, Colaco P, Goncavales P, Fernandes R, Keskinen KL, VilasBoas JP. Relationships between energy cost, swimming velocity and speed fluctuation in competitive swimming strokes. Portuguese J Sports Sci 2006: 6(2): 192-194.

Cappaert JM, Pease DL, Troup JP. Three-dimensional analysis of the men's 100-m freestyle during the 1992 Olympic Games. J Appl Biomech 1995: 11(1): 103-112.

Challis JH. A multiphase calibration procedure for the direct linear transformation. J Appl Biomech 1995: 11(3): 351-358.

Chollet D, Chalies S, Chatard JC. A new index of coordination for the crawl: description and usefulness. Int J Sports Med 2000: 21(1): 54-59.

Coleman S, Rankin A. A threedimensional examination of the planar nature of the golf swing. J Sports Sci 2005: 23(3): 227-234.

Craig AB, Pendergast DR. Relationships of stroke rate, distance per stroke, and velocity in competitive swimming. Med Sci Sports Exerc 1979: 11(3): 278-283.

D'Acquisto LJ, Costill DL. Relationship between intracyclic linear body velocity fluctuations, power, and sprint breaststroke performance. J Swim Res 1998: 13: 8-14.

Deffeyes J, Sanders R. Elliptical zone body segment modeling software: digitising, modeling, and body segment parameter calculation. In: Wang Q, ed. Proceedings of the XVII international symposium on biomechanics in sports. Beijing: The China Institute of Sport Science, 2005: 749-752.

Jensen RK. Estimation of the biomechanical properties of three body types using a photogrammetric method. J Biomech 1978: 11(8-9): 349-358.

Keskinen OP, Keskinen KL. Velocity profiles of competitive swimmers and triathlonists during an all-out $100-\mathrm{m}$ swim. In: XII FINA World Congress on Swimming Medicine ed. Goteborg: FINA, 1997: 351-356.

Leblanc H, Seifert L, Tourny-Chollet C, Chollet D. Intra-cyclic distance per stroke phase, velocity fluctuations and acceleration time ratio of a breaststroker's hip: a comparison between elite and nonelite swimmers at different race paces. Int J Sports Med 2007: 28(2): 140-147.

Manley PK, Atha J. Intra-stroke velocity fluctuations in paced breaststroke swimming. In: MacLaren D, Lees A, Reilly T, eds. Biomechanics and medicine in swimming - swimming science VI. London: E\&FN Spon, 1992: 151-159.

Payton CJ, Bartlett RM, Baltzopoulos V, Coombs R. Upper extremity kinematics and body roll during preferred-side breathing and breathholding front crawl swimming. J Sports Sci 1999: 17(9): 689-696.

Psycharakis SG, Cooke C, Paradisis GP, O'Hara J, Phillips G. Analysis of selected kinematic and physiological performance determinants during incremental testing in elite swimmers. J Strength Cond Res 2008: 22(3): 951957.

Psycharakis SG, Sanders R. Validity of the use of a fixed point for intra-cycle velocity calculations in swimming. J Sci Med Sport 2008 (In press. Published online at 05/03/2008. doi:10.1016/ j.jsams.2007.11.008).

Psycharakis SG, Sanders R, Mill F. A calibration frame for 3D swimming analysis. In: Wang Q, ed. Proceedings of the XVII international symposium on biomechanics in sports. Beijing: The
China Institute of Sport Science, 2005: 901-904.

Sanders RH. Breaststroke technique variations among New Zealand Pan Pacific squad swimmers. In: Troup JP, Hollander AP, Strasse D, Trappe SW, Cappaert JM, Trappe TA, eds. Biomechanics and medicine in swimming VII. London: E\&FN Spon, 1996a: 64-69.

Sanders RH. Some aspects of butterfly technique of New Zealand Pan Pacific squad swimmers. In: Troup JP, Hollander AP, Strasse D, Trappe SW, Cappaert JM, Trappe TA, eds. Biomechanics and medicine in swimming VII. London: E\&FN Spon, 1996b: 23-28.

Sanders RH, Wilson BD, Jensen RK. Accuracy of derived ground reaction force curves for a rigid link human body model. Int $\mathbf{J}$ Sports Biomech 1991: 7(4): 330-343.

Takagi H, Sugimoto S, Nishijima N, Wilson B. Differences in stroke phases, arm-leg coordination and velocity fluctuation due to event, gender and performance level in breaststroke. Sports Biomech 2004: 3(1): 15-27.

Togashi T, Nomura T. A biomechanical analysis of the novice swimmer using the butterfly stroke. In: MacLaren D, Lees A, Reilly T, eds. Biomechanics and medicine in swimming - swimming science VI. London: E\&FN Spon, 1992: 87-90.

Toussaint HM, Beek PJ. Biomechanics of competitive front crawl swimming. Sports Med 1992: 13(1): 8-24.

Toussaint HM, Beelen A, Rodenburg A, Sargeant AJ, DeGroot G, Hollander AP, Ingen Schenau GJ. Propelling efficiency of front-crawl swimming. J Appl Physiol 1988: 65(6): 2506-2512.

Toussaint HM, Den Berg CV, Beek WJ. Pumped-up propulsion during front crawl swimming. Med Sci Sports Exerc 2002: 34(2): 314-319.

Vilas-Boas JP. Speed fluctuations and energy cost of different breaststroke techniques. In: Troup JP, Hollander AP, Strasse D, Trappe SW, Cappaert JM, Trappe TA, eds. Biomechanics and medicine in swimming VII. London: E\&FN Spon, 1996: 167-171.

Vincent WJ. Statistics in Kinesiology, 3rd edn. Leeds: Human Kinetics Europe Ltd, 2005: 159-200. 